\section{Hydration of the Alite Phase in Portland Cement}

Calorimetric studies ${ }^{1-3}$ indicate that the rate of hydration of the alite phase (tricalcium silicate) in neat Portland cement pastes reaches a maximum 6-11 h after mixing. Two heating cycles, or periods of high heat evolution, are found with all cements; some show a third. The first, occurring immediately on mixing, is most likely due to the dissolving of soluble species and to an initial rapid reaction of the aluminate phase. The second cycle, which reaches a maximum 6-11 h after mixing, is assigned largely to the alite phase. The third heating cycle shown by some cements is attributed to the exhaustion of sulphate ion (gypsum), the breaking down of the ettringite coating on the tricalcium aluminate particles, and the subsequent rapid hydration of the remaining aluminate to $\mathrm{Ca}_{4} \mathrm{Al}_{2} \mathrm{O}_{10} \cdot \mathrm{XH}_{2} \mathrm{O}$. X-ray diffraction work in this laboratory offers direct evidence that the foregoing conclusion regarding the alite phase is correct.

Twenty grams of a Portland cement are made into a neat paste in a $50 \mathrm{-ml}$. polyethylene beaker using a waterto-cement ratio of $\mathbf{0 \cdot 2 5}$. Hydration is earried out in a carbon dioxide free atmosphere at 95 per cent relative humidity, $25^{\circ} \mathrm{C}$. After a predetermined period, the sample is broken up, and the hydration stopped by thoroughly washing with acetone. It is then dried in a vacuum oven for $1 \mathrm{~h}$ at $70^{\circ} \mathrm{C}$ and $10 \mathrm{in}$. of mercury. A 10 - $g$ portion is ground with 10 per cent $\mathrm{MgO}$ (periclase) by weight. The $2 \cdot 11 \AA \mathrm{MgO}$ line and the $1.76 \AA$ cement line are used for the $X$-ray analysis. The $1.76 \AA$ line in the diffraction pattern of a Portland cement is due mainly to the alite phase ${ }^{4}$. The small contribution that belite makes to this line is neglected.

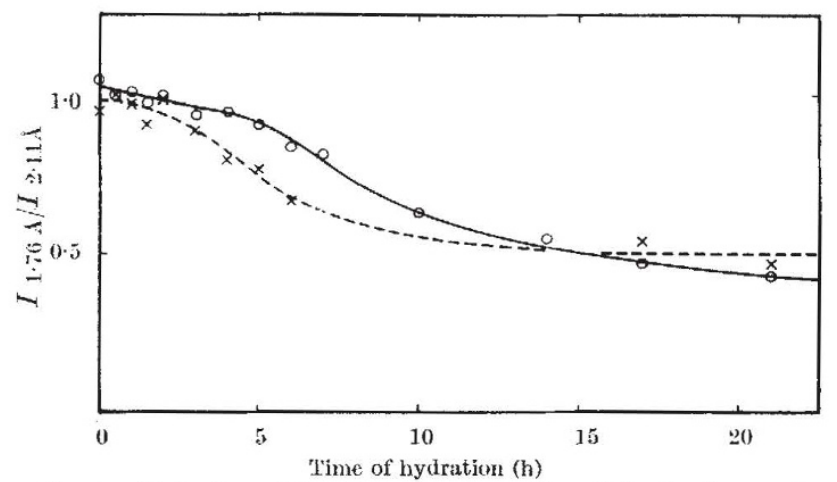

Fig. 1. Hydration of the alite phase in a Type I Portland cement. , No additive present; $x$, calcium ehloride added 1.0 per cent by weight of solid material

Fig. 1 is a plot of the ratio of the intensity of the $1.76 \AA$ line to the $2 \cdot 11 \AA \mathrm{MgO}$ line versus the time of hydration for a Type I Portland cement. Each point is the average of three samples. Much of the alite hydration occurs during the poriod $5-15 \mathrm{~h}$ after initially mixing the cement with water. The hydration rate reaches a maximum about $7 \mathrm{~h}$ after mixing. When calcium chloride is added to the mix water at a concentration equivalent to 1.0 per cent by weight of calcium chloride to anhydrous cement, the maximum rate of hydration occurs about $2 \mathrm{~h}$ earlier. The hydration of the alite phase in the presence of calcium chloride is also shown in Fig. 1. The slight difference in the points at which the two curves intersect the $y$-axis is due to the fact that the two experiments were carried out on two different diffraction units with slightly different counting periods.

Hydration of neat pastes on the X-ray goniometer itself in a specially designed sample compartment confirms the general nature of the alite reaction. When hydrated in this manner, the alite reaction is most rapid $5-10 \mathrm{~h}$ after mixing and reaches a maximum about $6 \mathrm{~h}$

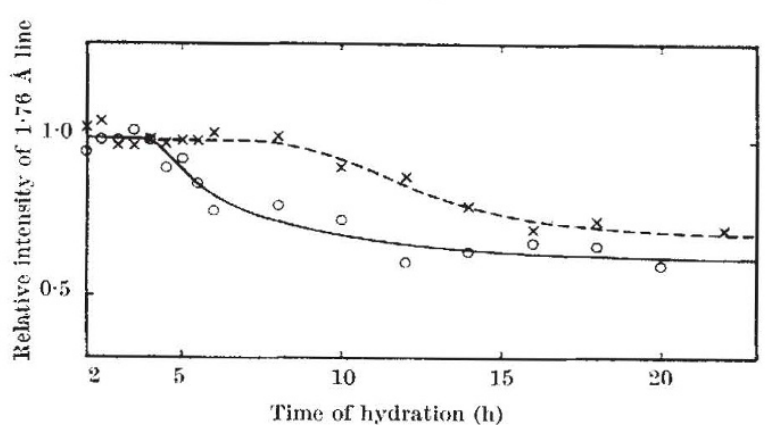

Fig. Hydration of the alite phase in a Type T Portland cement. 0 , $\mathrm{T}_{0}$ additive present; $x$, a commercial calcium lignosulphonate

after mixing. This technique also shows that a commercial calcium lignosulphonate delays the occurrence of this period of rapid hydration. In Fig. 2 the $y$-axis is relative. A strict quantitative comparison is not possible when the reaction is followed in the paste itself. This is due to preferred orientation problems and the lack of an internal standard stable in the alkaline cement-water system. No reliable numbers can be obtained during the first few hours of hydration while the paste is still plastic.

These results have an interesting relation to at least one physical property of cement pastes and mortars. Calcium chloride is commonly used to accelerate the set of Portland coments. ealcium lignosulphonate to retard it.

R. L. Angstant F. R. HuRLEY

Washington Research Conter,

W. R. Grace and Co..

Clarksville, Maryland.

${ }^{1}$ Lerch, W., and Bogue, R. H., J. Res. Nat. Bur. Stands., 12, 645 (1934!.

"Lereh, W., Proc. Amer. suc. Test. Mat., 46, 1252 (1946).

a Stein, H. N., J. App. Chem., 11, 474 (1961).

'Copeland, I. K., Brunauer, S., Kantro, D. I., Schulz, E. G., and Weist, C. H., Anal. Chem., 31, 1521 (1959).

\section{Preparation of Carcinogenic Polynuclear Hydrocarbons labelled with Tritium by Wilzbach's Method}

THE need for radioactive labelled polynuclear hydrocarbon carcinogens, to be used in biological investigations, led to an investigation of the feasibility of a tritium exehange procodure for their preparation. Wilzbach's method $^{1}$ offers a simple method of labelling complex eompounds which are comparatively difficult to synthesize. However, the procedure has its attondant problems in that. during exposure to tritium gas, concurrent with the oxchange reaction, tritium will tend to be taken up by reducible compounds present. The purification of the product must, therefore, ensuro removal of the high specific activity by-products.

Samples of benzo(a)pyrene, 7,12-dimethylbenz(a)anthracene and 20 -methylcholanthrene $(500 \mathrm{mg}$ of each) were exposed to tritium gas for 2 weeks. Tho specific activities of the products wore, respectively, $0 \cdot 80,0 \cdot 46$ and $0 \cdot 70$ me./mg. The distribution of radioactivity in the products was examined by chromatographing $15-100 \mu \mathrm{g}$ samples on Whatman No. 1 paper in a dimethylformamide-isooctane system ${ }^{2}$; the chromatograms were cut into sections and eluted. The ultra-violet absorption spectrum of each fraction was taken in isooctane and the radioactivity assayed by liquid scintillation counting. Recovery of radioactivity was virtually 100 per cent and of tho polynuclear hydrocarbons $90-100$ per cent (these being in the single fluorescent zone on each chromatogram). Less than 10 per cent of the radioactivity was associated with the fluorescent zones, the remainder being mainly at the starting line and below the fluorescent zone. These: 